\title{
A MODEL OF PRESERVING THE BUILT ENVIRONMENT
}

\author{
Richard G. Fritz and Warren McHone*
}

\section{Introduction}

The issue addressed here is the disposition of historic buildings. Historic sites offer examples of nonrenewable assets which may confer substantial benefits upon society in the form of merit goods. The subject gained considerable attention in the 1970 s as a partial answer to the problems associated with aging towns and regional development. The promoters of the movement argued that preserving historic buildings not only recycles exhaustible resources but could also relieve the pressures of inflation and unemployment as well as provide energy savings (Bever, 1976). Critics of the movement argued that this was just another attempt by the elite to displace the poor with the support of the state. The movement has been referred to by many titles, most recently historic preservation. The process is a simple one: start with an existing part of the built environment, e.g., an old building; repair, renovate, adaptively alter it, or in some way "fix it up." These activities have become some of the types of revitalization efforts of our older towns and cities (Cannon et.al., National Trust, N. Williams).

This paper reviews the arguments that have been presented by both supporters and critics of the historic preservation movement. The paper also attempts to lay the foundation for a more systematic study of the historic preservation process by presenting an econometric model which relates the decision to preserve or demolish a historic site to the major economic and noneconomic factors that are expected to influence the decision.

\section{Review of Economic Analysis}

Why preserve the historic resources of the built environment? Preservationists propose the conservation of historic resources based on non-economic grounds: Stipe (in Williams,

\footnotetext{
*University of Central Florida
}

et.al., 1983) lists seven benefits to society associated with the preservation decision:

1. Our historic resources are all that physically link us to our past.

2. We have lived with our historic and architectural heritage and it has become part of us.

3. The modern age of communication and other technological abilities have produced an era of increasing cultural homogeneity. Conservation provides an opportunity to maintain difference and uniqueness.

4. The preserved historic sites and structures relate to past events, eras, movements and persons that we feel are important to honor and understand.

5. The preservation is often justified because of the structures' intrinsic value as art.

6. The historic sites are simply more attractive than the essential tawdriness of much contemporary design and construction.

7. Preservation can serve an important human and social purpose in our society. Ancestor worship and aesthetic motivations are no longer enough. Preservation offers hope in comparison to a rapidly deteriorating urban environment.

This approach follows the European tradition, where the argument for preserving the historical built environment is predicated on the conviction that the conservation of old buildings is more than a matter of just providing structures in a practical manner. Preserving tangible links to the past is essential to the health and humanity of a community environment. Massive destruction of a community's physical fabric can remove much of what provides a stabilizing influence on people's lives. Stability in the built environment can instill confidence in the future. The dislocation and emotional feeling of loss can break the pride and respect which ordinary citizens have in their community (Williams, 1979, p. 69). 
Many good examples exist. In Verona, Italy, the retreating German army damaged the Roman bridge that provided a southern entrance to the town. After the war, the river was diverted north of town through a newly constructed channel during the low flow summer months in order to rebuild the Roman bridge. The original block and stone were there in the dry river bed and were used to rebuild the bridge. Preserving the bridge left the image of Verona consistent with its historic past. On a much larger scale, 90 percent of the historic buildings of Warsaw, Poland were destroyed in an attempt to raze the city. The destruction was of such a scale that serious consideration was given to leaving Warsaw in ruins as a testimony to the atrocities of the war. The decision was finally made to rebuild the city as the last victory in the unbending resistance against enemy violence. Using what remained of the partly ruined and damaged structures, the city was reconstructed with attention to historic detail.

In contrast to the European experience of reconstruction of damaged structures, cities such as Paris and Florence did not suffer physical destruction during the war. Their cases have evolved through a process of preservation rather than reconstruction. The heart of Florence has had little physical alteration to its cityscape for three hundred years.

The perceived benefits that accrue to society from historic preservation are generally difficult to identify and quantify. As a result they have not received much emphasis in the economic literature. A few scholars, however, have attempted to identify the "social" value of preserving the built environment. Lynch (1960, 1981) has discussed the psychological value of a consistent city "image," while Smith (1977) has attempted to develop a method of assessing the aesthetic value of the city-scape.

The approach of Stipe, Lynch and Smith (and a few others) avoids the critical question of the efficient societal use of the historic resources. That is, with no explicit attempt made at assessing the likely social benefits or social opportunity costs arising from a protection or demolition decision, it is not clear whether we are conserving too many or too few buildings (Aylen).

Economists assume that there is some logic to our actions with respect to the use of resources and that the study of these actions will reveal that logic and thereby the relative value we individually and collectively associate with those resources. The "historical" preservationist (such as Stipe, Lynch and Smith, above) may argue that economics can only deal with commercial or market values. Aesthetic values, social values, cultural values, etc. are outside the domain of economics. In estimating the economic value of the quality of life, Power (1980, p. 84) concedes that the mingling of various qualities in a single good or service which allows it to satisfy several needs simultaneously does raise conceptual problems for conventional analysis. Yet Power argues that the mere presence of aesthetic, cultural or social considerations does not indicate that economic analysis is either in principle inappropriate or conceptually impossible. The problem of establishing the value of environmental resources, natural or built, is not the difficulty individuals have in establishing what that value is to themselves, but the difficulty an observer has in determining what value judgement the individual has in fact made. Market settings explicitly offer observable, quantitative information transactions between individuals. This provides preliminary if somewhat flawed data from which to begin an evaluation of the resource. Irreplaceable resources present valuation problems that are more difficult than the valuation where a choice among goods and services which are relatively strong substitutes for each other and whose supply can be increased through some operable production process.

Krutilla and Fisher define three classes of irreplaceable assets: gifts of individual genius, gifts of collective genius, and gifts of nature. Where the preservation of irreplaceable assets have opportunity costs (the opportunity returns foreclosed from alternative uses of the resources reflected in, or required by, preservation), these costs must be considered (pp. 7071). Once demolished, historic buildings cannot be resupplied. Like the supply of other historically provided assets, reductions in the stock of historic structures are irreversible. Complicating current decisions in irreversibly supplied goods is the uncertainty concerning future preferences. The risks associated with the alternatives of conservation or demolition are asymmetrical in that over conservation may be remedied in later time periods whereas there is no authentic remedy for over demolition. Arrow and Fisher (1974) argue that the benefits of 
depleting an irreplaceable resource may be overstated if there is a possibility that realized costs and benefits from the earlier stage of development give rise to a change in their expected values for later periods. Because the loss function is asymmetrical, Aylen (1978, p. 410) has concluded that the long run optimal stock of historic buildings may be maintained for a while at a point where the current marginal benefits of preservation are below the current marginal social opportunity costs of retention while the returns from redevelopment of historic sites are decreasing over time relative to returns from preservation. This position is confirmed by Krutilla and Fisher (1975) who argue that it is optimal to stop develpment of an irreversible asset while current net benefits still exceed current marginal social opportunity costs of retention as long as the returns from redevelopment of historic sites are decreasing over time.

Following Herfindahl and Kneese (1974) the simple but unrealistic assumption that the marginal utility of money is equal, between individuals, and constant over the range of effects being considered allows the research to focus on efficiency analysis separately from distribution. Relaxing these assumptions will not interfere with the results (pp. 236-246). The efficiency objective is then to maximize the positive difference between benefits (measured by the willingness of beneficiaries to pay for outputs) and costs (the willingness of persons to pay to keep resources in alternative employments).

Historic buildings have both private and public good characteristics. Thus the gross private benefit is measured by the area beneath the Marshallian demand curve for the historic site. Let the general demand function be $P=f(x)$ where $x$ represents the level of output (preservation of built environment). Now $B=g(x)$, the total private benefit function, for some level of output $a$ is given by $\int_{0}^{a} f(x) d x$. Since $g$ is the total benefit function, $f$ may be referred to as the marginal benefit function.

If the historic site is preserved, the standing building deprives society of any alternative use for the site. The gross costs $\mathrm{C}(\mathrm{A})$ are the money value of goods (or services) foregone throughout the economy to preserve and use the site A. Let the net private benefits be the difference between willingness to pay $\mathrm{B}(\mathrm{A})$, and the value of the goods and services displaced by the pres- ervation project. By designating $\mathrm{Y}=\left(\mathrm{y}_{1}, \mathrm{y}_{2}, \ldots\right.$ $\left.y_{m}\right)$ as a vector of outputs from the project and $X$ $=\left(\mathbf{x}_{1}, \mathbf{x}_{2}, \ldots \mathbf{x}_{\mathrm{m}}\right)$ as a vector of inputs to the project, we may develop the following ranking function

$$
\mathrm{W}(\mathrm{A})=\mathrm{E}(\mathrm{Y})-\mathrm{C}(\mathrm{X})
$$

where $\mathrm{W}(\mathrm{A})$ are the net benefits of the project. $\mathrm{C}(\mathrm{X})$ is the cost of inputs used efficiently, and $\mathrm{E}(\mathrm{Y})$ is the benefit measured as the area under the demand curve, for output $y_{j}$,

$$
\mathrm{E}\left(\mathrm{y}_{\mathrm{j}}\right)=\int_{\gamma} \mathrm{D} \mathrm{D}(\eta) \mathrm{d} \eta
$$

Summing the aggregate benefits of individual outputs, and adjusting for a discount factor of a future benefit stream yields the familiar marginal conditions for a maximum:

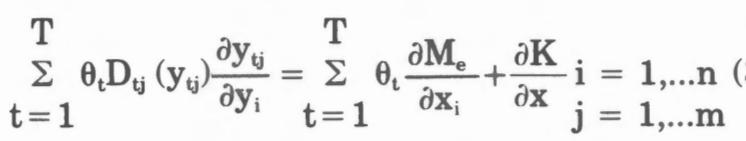

where $\quad \theta_{t}=$ Discount factor for period $t$.

$$
\begin{aligned}
& D_{t j}\left(y_{t j}\right)=\text { Demand price in period } t \text {. } \\
& \frac{\partial \mathrm{y}_{\mathrm{tj}}}{\partial \mathrm{x}_{\mathrm{i}}}=\begin{array}{l}
\text { Marginal product of the } i \text { th } \\
\text { input when devoted to the } j
\end{array}
\end{aligned}
$$

In order to evaluate the public and private sector activity regarding historic buildings, we must determine if market forces automatically obtain the necessary conditions for maximizing net benefits. Clearly the requirements of equation (3) are met in a perfectly competitive market (Dasgupta and Heal, 1979, pp. 283-321). The problem of evaluation centers on the measure of the willingness of the consumers to pay for the output of the preservation of the site. The public good characteristic of the decision means that often consumer surplus must be estimated. This has resulted in most economic analysis of historic preservation oriented toward individual studies.

The case study method begins by asking what economic benefits there are in recycling and 
extending the life of the built environment. Bever attempted to outline the major attributes. Rehabilitation of a building is cost effective. That is, it is less costly to recycle a structure than it is to build a new building which will provide the same or similar service. Unfortunately a sweeping generalization can be grossly misleading and a case by case study is always necessary. However, positive reports have come from several resources. Ranne and Raynor Warner in 1978 found that average renovation costs ranged from $\$ 15$ to $\$ 40$ per square foot compared to the then current highrise office building costs of about $\$ 80$ per square foot. Thus, if the building can be purchased for less than $\$ 40$ per square foot then rehabilitation is a competitive alternative. In 1976, the National Trust for Historic Preservation conference on the "Economic Benefits of Preserving Old Buildings" illustrated through case studies that rehabilitating the built environment was from $25-33 \%$ less than comparable new construction.

This does not imply that every old structure is a worthy rehabilitation project. Technical questions of structural integrity are always necessary. Physical neglect may be too advanced to warrant preservation. However, there may still be a strong case for retaining the building's shell or facade. The value of retaining the image of the cityscape is presented by Lynch.

Another case has been made for historic preservation on the grounds of the relative labor participation in the cost figures. The Department of Interior has estimated that rehabilitation projects are as high as $75 \%$ labor intensive, as compared to $50 \%$ for new construction (Bever). Thus, funds used for historic preservation have a greater impact on unemployment than the alternative of using those funds on the construction of new buildings. In a blighted area of Brooklyn, the Bedford-Stuyvesant Restoration Corporation has used their restoration project to teach welding, masonry and painting to the neighborhood's unemployed. It is not unusual to find the highest concentration of old structures in areas where the city's unemployment problems are greatest. Unfortunately follow-up data on the post-project employment record is not available but even if all of the 3,351 workers who participated in the BedfordStuyvesant training program returned to the list of unemployed, their training was at least a temporary alternative to welfare and their physical output will endure.

The Energy Research and Development Administration has argued that historic preservation is both energy and resource efficient. ERDA estimated that rehabilitation is about $23 \%$ less energy consuming than new construction. The First and Second Laws of Thermodynamics reinforce the logic of recycling the built environment. Less raw materials are necessary when rehabilitating (75\% labor intensive) and therefore the "quality" of the existing stock of natural resources is less degraded (the entropy rule).

Rehabilitation has proven to be an important method of revitalizing urban areas (Williams, R., 1979, and Williams, N., 1983). The private sector response is the result of a typical income spending multiplier effect usually addressed in regional development analysis. However, beyond the multiplier analysis is the psychological effect the demonstration of public commitment has on the town or neighborhood. Another psychological benefit that preservationists point to is the increased productivity of workers who find the environment of rehabilitated old buildings more pleasing than the sterile atmosphere of new construction. However appealing, the authors have not been able to find documentary support for this claim.

Revitalization of the depressed older area may result in increased property tax base and revenues (Listokin). The increased employment and spending result is an increase in income tax and sales taxes. Both the private and public benefit-cost analysis calculations seem to support this type of investment. As Cannon, et al. point out, the use of government subsidies to historic preservation or even the designation of neighborhoods for preservation and renewal demonstrates a public commitment which generally spurs owners to maintain their properties and thus reassure inmigrants that the neighborhoods have long lives ahead of them. In a very real way, the use of public subsidy or the designation of a neighborhood as a historic district reveals the 'meritoriousness' of the project.

The Advisory Council on Historic Preservation of the U.S. Government sponsored several studies between 1977 and 1979, reviewing the practical advantages of historic preservation. The Contribution of Historic Preservation to Urban Revitalization conclusions included: 
1. New businesses have been found.

2. Private investments have been stimulated.

3. Tourism has been stimulated.

4. Property values have been increased.

5. The quality of life and the sense of neighborhood and community pride have been enhanced.

6. New jobs have been created.

7. Land use patterns are compatible.

8. Property and sales taxes have increased.

9. Pockets of deterioration and poverty have been diluted.

However, as with all social decisions, the results are not unequivocal. The social justice of historic preservation must still be questioned. Edmund Bacon's Society Hill in Philadelphia "unslummed" the brick townhouses and replaced the low income tenants with 50,000 upper income residents. Bacon is reported as philosophical about the poor who were displaced: "You have to start somewhere and this at some human cost, was a proper place to start." (Williams, R., p. 71) Other examples include Burlington, Vermont's Ice House project. The recipients of a $\$ 50,000$ historic preservation grant, two local investors transformed a decaying old building into a posh restaurant on Burlington's lake front. The previously low income residential neighborhood has "benefited" from the revitalization effort. Rehabilitation has cost them higher rents and forced relocation. Those who remain behind are unable to shop in the new shops or eat in the new restaurants that have opened in this "preservation district." The human cost can not be philosophically tossed aside.

The urban poor can benefit from historic preservation. They can respect and enjoy the emotional benefits of the built environment as long as the preservation does not destroy their lives, jobs and families. A community based and controlled non-profit development corporation is a vehicle that has proved to be an effective vehicle in historic preservation. In Orlando, Florida, such a method has resulted in the preservation of the only public educational facility available to the black community during the years of segregated schooling. Located in the heart of the black residential and business community, the preservation project has brought new life to the neighborhood's business and social life. The success of this project appears to be the result of a participatory, dem- ocratic community process.

The survey presented above is a generally positive endorsement of historic preservation projects. Yet there are other opportunities for the built environment than revitalization. Obviously, the structure will either be replaced by a new one or, after sufficient deterioration, the property will be left vacant. The first step to understanding the replacement or rehabilitation decision is to evaluate what role the traditional market forces play. As for the vacancy problem, there is considerable concern. Vacancy results in negative aesthetic effects (blight and urban sprawl), private and social costs and fiscal consequences which result in reduced public revenues (Witte and Bachman). In the next section of this paper a model will be developed to help evaluate these issues. The approach followed in this study does not use a case study procedure. Rather a cross sector analysis of market activity is attempted.

\section{A Supply Model of Historic Preservation}

Adopting the normative position that historic preservation is a desirable social goal, the merit good aspects of this activity and the associated divergence between its marginal social benefits and marginal private benefits means that too few historic site preservations will occur. This raises two critical questions. First, what are the factors that determine the private sector's supply of preserved historic sites and secondly, how much does this supply fall short of the socially desirable level? This section provides information pertinent to the first of these questions by examining the relationship between the decision to place a given site in a certain state of preservation and the major economic and noneconomic factors that are expected to influence the decision. ${ }^{1}$

The influencing factors in the historic preservation decision can be grouped into the following three categories:

Intrinsic Historic Significance: These are the characteristics of a particular site that reflect its historic significance such as age, role in historic events, historic ownership, etc. These characteristics determine the benefits to society that would be foregone by not placing the site in a particular preservation state. The higher these benefits the more likely a site is to be placed in a higher state of preservation. It is, of course, difficult, if not impossible, to design an index that will satisfactorily convey relative 
historic significance. Rather than attempting this, the approach taken here is to use proxy variables which, in part, reflect the intrinsic historic value of a site. The proxies used are age of the structure, official designation as a historic site and the estimated market value of the site in its current state of preservation.

Direct Preservation Costs: These are the direct cost outlays on labor and materials required to renovate the site. These also include the costs of maintaining the site. The lower these costs, the more likely a site is to be placed in a higher state of preservation.

Imputed Preservation Costs: These are the opportunity costs of placing a site in a particular state of historic preservation. Such things as the site's alternative use and its general accessibility to centers of business activity will determine the cost. The lower these costs, the more likely a site is to be placed in a higher state of preservation.

\section{The Model}

To assess the influence of the above factors on the historic site preservation decision, a series of four qualitative response models of the general form

$P_{i j}=f\left(A_{i}, H_{i}, M_{i}, R_{i}, S_{i}, D_{i}, U_{i}\right) j=1, \ldots ., 4$

were estimated. The dependent variable in each of the models, $\mathrm{P}_{\mathrm{ij}}$, is a dichotomous variable that takes on a value of 1 if site $i$ is in preservation state $j$ and a value of 0 if it is not. The four states of preservation are defined as follows:

High Preservation State: Three types are considered to be in this state - (1) sites with substantial renovation which include compatible facade changes and/or new construction which is consistent with the original design of the structure, (2) sites with complete renovation which include restoration of historic facade, but major adaptive use of the interior and (3) sites with complete restoration which return the structure to its original appearance (or to a period for which the site is well known).

Medium Preservation: The sites included in this state are those that have been renovated so as to maintain some but not all of the qualities and contributions that made the structure a candidate for protection. This includes sites in which new construction of a noncompatible nature is present. The main difference between sites in this state and those in the higher state is the treatment of the facade.
Low Preservation: This state includes sites that have received only minor renovation or stabilization efforts which attempt to maintain the structure as is with the intent of retarding further deterioration.

No Preservation: Sites included in this category are those in which the structure has been completely demolished. In some cases the structures have been replaced by reconstructed buildings which are historic in appearance but are essentially new buildings.

The independent variables are the age of the structure, $A_{i}$; a dichotomous variable, $H_{i}$, which takes on a value of 1 if the site has official designation as a historic site and a value of 0 if it doesn't; the site's market value per square foot, $\mathrm{M}_{\mathrm{i}}$; the renovation cost per square foot required to place the site in its present state of preservation, $R_{i}$; a dichotomous variable indicating the basic structural material of the site's building $\left(S_{i}=1\right.$ if the material is stone or brick and $\mathrm{S}_{\mathrm{i}}=0$ otherwise); the location of the site (measured as the reciprocal of distance in miles to the central business district), $D_{i}$; and a dichotomous variable indicating the site's current use $\left(\mathrm{U}_{\mathrm{i}}=\right.$ 1 if the site is currently used for commercial purposes, $U_{i}=0$ otherwise).

Based on the earlier discussion it is expected that older age $\left(A_{i}\right)$, official historic designation $\left(H_{i}=1\right)$, higher market value $\left(M_{i}\right)$ and stone or brick structural material $\left(S_{i}=1\right)$ will all contribute positively to a site's chances of being placed in a higher state of preservation. Higher renovation costs $\left(R_{i}\right)$, proximity to the central business district $\left(D_{i}\right)$ and use of the site for commercial purposes $\left(U_{i}=1\right)$ are expected to decrease a site's chances of being placed in a higher state of preservation.

\section{Empirical Results}

The data used to estimate the parameters of the four models described above are observations from 55 identifiable historic sites in Chittenden County, Vermont. The sample consists of thirty-six (36) sites that had been preserved to one extent or another and nineteen (19) that had been demolished or replaced.

The data was obtained through the graduate history program in Historic Preservation of the University of Vermont; the Vermont State Archives; local town offices of the Assessors, Building Inspectors, Planners, Community Development; local architects, contractors/ developers, and site owners. An attempt was 
made to include all types of "preservation" sites (0-10 years), sites where replacement has taken place (0-10 years) and all current vacant sites within the closely settled towns of the county (Burlington, Winooski and South Burlington). The vacant sites were included in the data set only if they currently had a standing structure or had a structure recently demolished (within the last 10 years). The vacant sites that resulted from the "bulldozer method" of urban renewal in the 1960's were not included. It was felt that including the characteristics of these demolished structures would yield an undesirable data bias because these structures were taken down in mass rather than through the application of individual decision.

The results obtained by estimating linear specifications of the historic preservation decision models are presented in Table I. The four equations represented by the columns of this table can be interpreted as linear probability functions. The individual coefficients indicate the marginal contribution of their associated variable to a site's probability of being placed in the preservation state listed at the top of the column.

The overall measures of significance for the four models (i.e., $R^{2} s$ ) suggest that the set of influence variables is more adept at explaining the extreme states of preservation (i.e., High or Demolished) than the inbetween states. One possible interpretation of this result is that the "Medium and Low" preservation states are mainly used as holding states for sites of questionable historic significance or with uncertain direct and/or imputed costs.

A survey of the specific coefficients in the table indicates that a limited set of the included factors is significantly related to a site's preservation state probability. The factors that raise a site's probability of being placed in a "High Preservation State" are official historic site designation (i.e. $\mathrm{H}_{\mathrm{i}}=1$ ) and being originally constructed from stone or brick (i.e., $\mathrm{S}_{\mathrm{i}}=$ 1 ). These same two factors also have a significant diminative effect on a site's probability of

TABLE I

Factors Influencing the Historic Preservation Decision

\begin{tabular}{ccccc}
\hline Influence & High & Medium & Low & Demolished \\
\hline Variables & $.37^{*}$ & -.20 & .03 & $.81^{* * *}$ \\
\hline Intercept & $(1.83)$ & $(1.04)$ & $(.14)$ & $(3.91)$ \\
& -.002 & .0007 & .001 & -.0005 \\
$\mathrm{~A}_{\mathrm{i}}$ & $(1.04)$ & $(.45)$ & $(.95)$ & $(.28)$ \\
& $.63^{* * *}$ & .04 & $-.30^{* * *}$ & $-.37^{* * *}$ \\
$\mathrm{H}_{\mathrm{i}}$ & $(5.75)$ & $(.38)$ & $(2.90)$ & $(3.33)$ \\
& -.008 & $.02^{* * *}$ & .004 & $-.01^{* * *}$ \\
$\mathrm{M}_{\mathrm{i}}$ & $(1.44)$ & $(3.28)$ & $(.85)$ & $(2.48)$ \\
& .005 & -.005 & -.0009 & .001 \\
$\mathrm{R}_{\mathrm{i}}$ & $(1.08)$ & $(1.24)$ & $(.22)$ & $(.31)$ \\
& $.27^{* *}$ & -.03 & .13 & $-.37^{* * *}$ \\
$\mathrm{~S}_{\mathrm{i}}$ & $(2.15)$ & $(.24)$ & $(1.13)$ & $(2.92)$ \\
& -.004 & -.05 & $.10^{* *}$ & -.04 \\
$\mathrm{D}_{\mathrm{i}}$ & $(.07)$ & $(1.08)$ & $(2.07)$ & $(.82)$ \\
& $-.31^{* * *}$ & .07 & .13 & .11 \\
$\mathrm{U}_{\mathrm{i}}$ & $(2.68)$ & $(.60)$ & $(1.23)$ & $.92)$ \\
$\mathrm{R}^{2}$ & $.54^{* * *}$ & $.22^{*}$ & $.33^{* * *}$ & $.53^{* * *}$ \\
$(\mathrm{~F})$ & $(7.91)$ & $(1.94)$ & $(3.28)$ & $(7.38)$ \\
\hline
\end{tabular}

$t$ values in parenthesis under coefficient

* coefficient is significant at $10 \%$ level

** coefficient is significant at $5 \%$ level

*** coefficient is significant at $1 \%$ level 
being placed in a "Demolished State" (these effects are indicated by the negative signs on the coefficients for $\mathrm{H}_{\mathrm{i}}$ and $\mathrm{S}_{\mathrm{i}}$ in the last column of Table I).

The only other factors that appear to affect a site's probability of being in either of the extreme states (i.e., High or Demolished) are the site's alternative use $\left(\mathrm{U}_{\mathrm{i}}\right)$ and the market value of the historic site $\left(\mathrm{M}_{\mathrm{i}}\right)$. More specifically, sites that are used for commercial purposes (i.e., $U_{i}=1$ ) are less likely to be placed in a "High State of Preservation" and sites with high market value $\left(M_{i}\right)$ are less likely to be demolished.

\section{Conclusion}

This model should not be used to construct a set of historic preservation "rules." Rather the lesson from this study is what was found to be insignificant as much as it is a lesson focusing on the decision model's indication of significant variables. Age, renovation costs and the location variable (distance) were not found to be significantly influential in determining the state of preservation. Yet these are typical characteristics of the "market forces" described by the literature as impacting the use of urban spaces (Muth, 1969; Henderson, 1977). The other variables appear to have a role in the determination of the state of preservation, yet with inconsistent results. Note from Table I that market value, $\mathbf{M}_{\mathrm{i}}$, is significant in determining when a site is not likely to be demolished although it does not significantly influence the condition of a high state of preservation. Similarly, the current use of the site, $U_{i}$, plays an important role in determining the high state of preservation but is not an important determinant for the condition of demolition.

Demolished structures are prominently explained by the equation's intercept. This implies that variables in the model insufficiently describe the act of demolishing historic structures. The probability profile tells us that buildings with historic designation and high market value made out of brick or stone are least likely to be demolished. At the other extreme, buildings with historic designation, made of brick or stone and used for commercial purposes are most likely to reach the highest state of preservation.

Yet to be accomplished is a careful investigation into the less traditional market elements. Historical preservation is an important tool of urban and regional analysis and economists need to become more familiar with its causes and effects. Unfortunately the difficulty and expense involved in collecting data in this field has hindered the systematic study by social scientists.

The arguments of preservation critics have not yet been reasonably answered. In many ways, historic preservation is superior to previous attempts at restoring life to older urban areas. However, the human costs of displacement cannot be philosophically dismissed by planners and developers. Economists helped produce the facts and figures of the 1960s urban renewal programs which are so highly criticized today. Historic preservationists have turned to economists to justify their recent surge in programs. These programs will have to be carefully balanced with the needs of the people whose neighborhoods are to be affected.

\section{FOOTNOTES}

1The second question, i.e., the socially desirable level of historic preservation, is a considerably more difficult question to answer empirically. The question is left open for philosophical discussion until a method is devised for estimating society's marginal social benefit curve for preserved historic sites.

\section{REFERENCES}

Arrow, K.J. and Fisher, A.C. (1974). "Preservation, Uncertainty and Irreversability," Quarterly Journal of Economics Vol. 88, No. 2, May, pp. 312-319.

Aylen, Jonathan (1978). "The Social Cost-Benefit Analysis of Historic Building Restoration: A Case Study of Barlaston Hall, Staffordshire," Contemporary Economic Analysis, M.J. Artis and A.R. Nobay, (eds.), London: Croom Helm Publishers, pp. 409-447.

Bever, Thomas, "The Economic Benefits of Historic Preservation," Heritage Conservation and Recreation Service, U.S. Department of Interior, May, 1978.

Cannon, Donald, M. Leanne Lachman and Arlyne Bernhard. "Identifying Neighborhoods for Preservation and Renewal," Growth and Change, Vol. 8 (1), January 1977, pp. 35-38.

Dasgupta, P.S. and G.M. Heal, Economic Theory and Exhaustible Resources. Cambridge, G.B.: Cambridge University Press, 1979.

Gordon, Ray. "Valueing Historically Significant Properties," The Appraisal Journal, April 1974, pp. 200-209.

Henderson, J. Vernon. Economic Theory and the Cities. New York: Academic Press, 1977.

Herfindahl, Orris and Allen V. Kneese, Economic Theory of Natural Resources. Columbus, Ohio: Charles E. Merrill Publishing Co., 1974.

Krutilla, John V. and Fisher, A.C., The Economics of Natural Environments: Studies in the Valuation of Commodity and Amenity Resources. Baltimore: John Hopkins for Resources for the Future, 1975.

Listokin, David. Landmarks Preservation and the Property Tax. New Brunswick, N.J.: Center for Urban Policy Research, Rutgers University, 1982. 
Lynch, Kevin. The Image of the City. Cambridge Mass.: The MIT Press, 1960.

. The Theory of Good City Form. Cambridge Mass.: The MIT Press, 1981.

Muth, Richard F. Cities and Housing. Chicago: University of Chicago Press, 1969.

National Trust for Historic Preservation, Economic Benefits of Preserving Old Buildings. Washington, D.C.: The Preservation Press, 1976.

Power, Thomas. The Economic Value of the Quality of Life. Boulder, CO: Westview Press, Inc., 1980.

Segal, David. "Instruments in Historic Preservation," Cambridge, Mass.: Discussion Paper (D78-16) Department of City and Regional Planning, Harvard University, September 1978.

Smith, Peter. The Syntax of Cities. London, England: Hutchinson and Company, 1977.
The Contribution of Historic Preservation to Urban Revitalization, Advisory Council on Historic Preservation, (Washington, D.C.: Government Printing Office, 625046-1229, 1979).

Warner, Ranne P. and Raynor M., "Saving Old Buildings Makes Economic and Cultural Sense." Harvard Business Review. March, 1978.

Williams N., Edmund H. Kellogg and Frank B. Gilbert (eds.), Readings in Historic Preservation. New Brunswick, N.J.: Center for Urban Policy Research, Rutgers University, 1983.

Williams, Richard, "Our Older Cities are Showing Age but also Showing Signs of Fight," Smithsonian. January, 1979 , pp. 66-74.

Witte, Ann and James Bachman, "Vacant Urban Land Holdings: Portfolio Considerations and Owner Characteristics," Land Economics, November 1977. 